\title{
The effects of selected factors on pedestrian crossings in urban areas
}

\author{
Lucyna Gumińska ${ }^{1, *}$ \\ ${ }^{1}$ Gdansk University of Technology, Faculty of Civil and Environmental Engineering, Gdansk, Poland
}

\begin{abstract}
Pedestrian crossings are designed to help pedestrians cross a road. There are at-grade pedestrian crossings with or without traffic lights and grade separated crossings such as subways and footbridges. Pedestrian crossings may be located next to a junction or on road sections between junctions. Where at-grade crossings are involved, pedestrians and motorists interact, which may lead to dangerous situations and road traffic conflicts. These mutual interactions between infrastructure users determine how pedestrian crossings operate. They also affect the operation of junctions, if located next to them. The article presents the most important factors that affect the operation of pedestrian crossings. Because of the multiplicity of factors, only one of the parameters of traffic factors is described in detail.
\end{abstract}

\section{Introduction}

Pedestrian crossings are designed to help pedestrians cross a road [1]. There are at-grade pedestrian crossings with or without traffic lights and grade separated crossings such as subways and footbridges [2]. Pedestrian crossings may be located next to a junction or on road sections between junctions. Where at-grade crossings are involved, pedestrians and motorists interact, which may lead to dangerous situations and road traffic conflicts [3]. These mutual interactions between infrastructure users determine how pedestrian crossings operate. They also affect the operation of junctions, if located next to them.

The article presents the most important factors that affect the operation of pedestrian crossings. Because of the multiplicity of factors, only one of the parameters of traffic factors is described in detail.

"The research is conducted under the FLOW project. The project received funding from the European Union's Horizon 2020 research and innovation programme under grant agreement No 635998. This article reflects only the author's view and the Agency is not responsible for any use that may be made of the information it contains"

\section{Factors influencing the operation of pedestrian crossings}

Pedestrian crossings should ensure that people can move across them safely, comfortably, efficiently and economically whilst minimising the negative environmental impacts. These objectives are mutually dependent. Efficiency here is a measure of quality, i.e. capacity. Safety is determined by traffic layout, geometry and pedestrian and driver visibility. Traffic conditions translate into lost time.

\footnotetext{
* Corresponding author: lucgumin@.pg.gda.p1
} 
Pedestrian safety analyses that compare Polish domestic data and those from other European countries show that Poland features a very high rate of pedestrian fatalities, in excess of $30 \%$ of all road deaths in 2015. This is shown in Figure 1. While there is a significant difference between the $1990 \mathrm{~s}$, with pedestrian mortality in Poland per $1 \mathrm{~m}$ population at app. 70 people, and the post-2010 data at 30 people (Fig.2), the figure continues to be extremely high. It is clear that more investigation into the causes and factors of this is necessary.

It is important to know that Poland does not conduct research on the hazards that pedestrians are exposed to in urban and rural areas. If it did, efforts could be undertaken to understand the effectiveness and accuracy of treatments. As set out in the National Road Safety Programme for the Years 2013 - 2020, implemented by the National Road Safety Council, pedestrian safety is a strategic action under the pillar Safety of People.

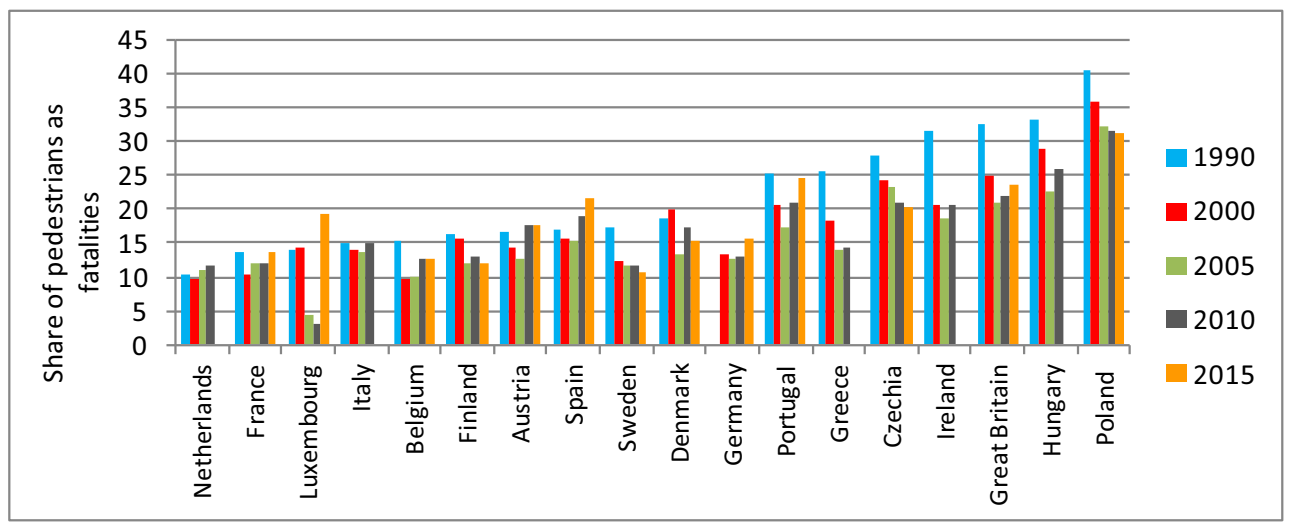

Fig. 1. Share of pedestrian fatalities, based on [4].

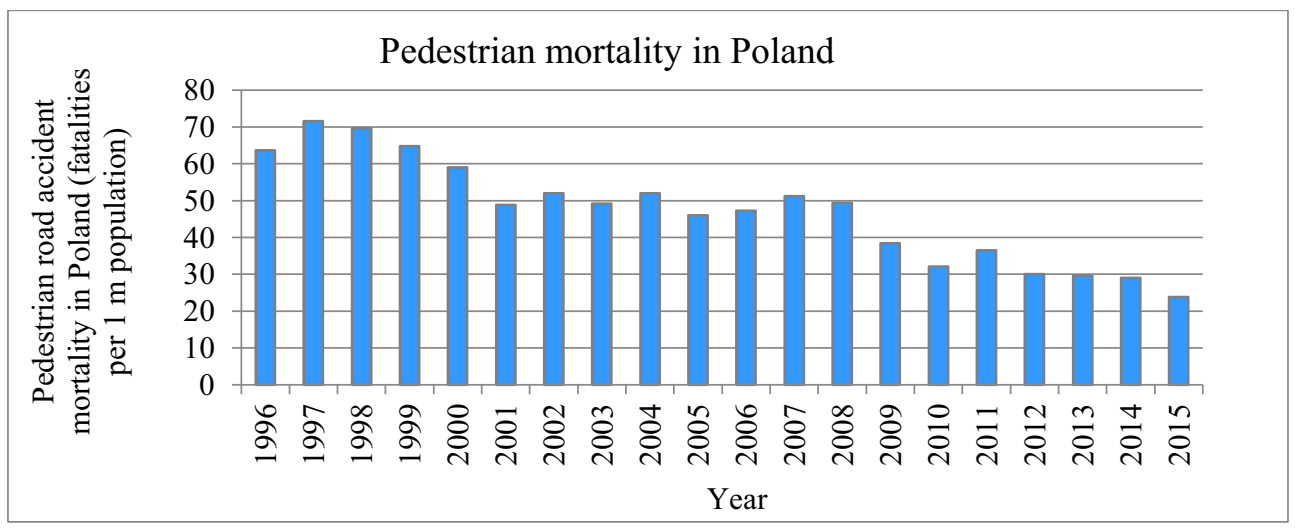

Fig. 2. Pedestrian accident mortality in Poland, based on [4,5].

Speed is a major factor in road accidents involving vehicles and pedestrians and determines accident severity. Fig. 3 shows the likelihood of a pedestrian death in relation to vehicle speed. Swedish researchers Erik Rsen and Ulrich Sander found that their predecessors based their findings on pedestrian serious injury or death which overestimated the risk of becoming a fatality [6,7]. Their research shows that the probability of pedestrian fatality is $100 \%$ for vehicle speed of app. $120 \mathrm{~km} / \mathrm{h}$, while other scientists such as R. Anderson claimed it is app. $57 \mathrm{~km} / \mathrm{h}$ and E Pasanen, G. Davis and C. Oh at app. $100 \mathrm{~km} / \mathrm{h}$ [8-10]. 


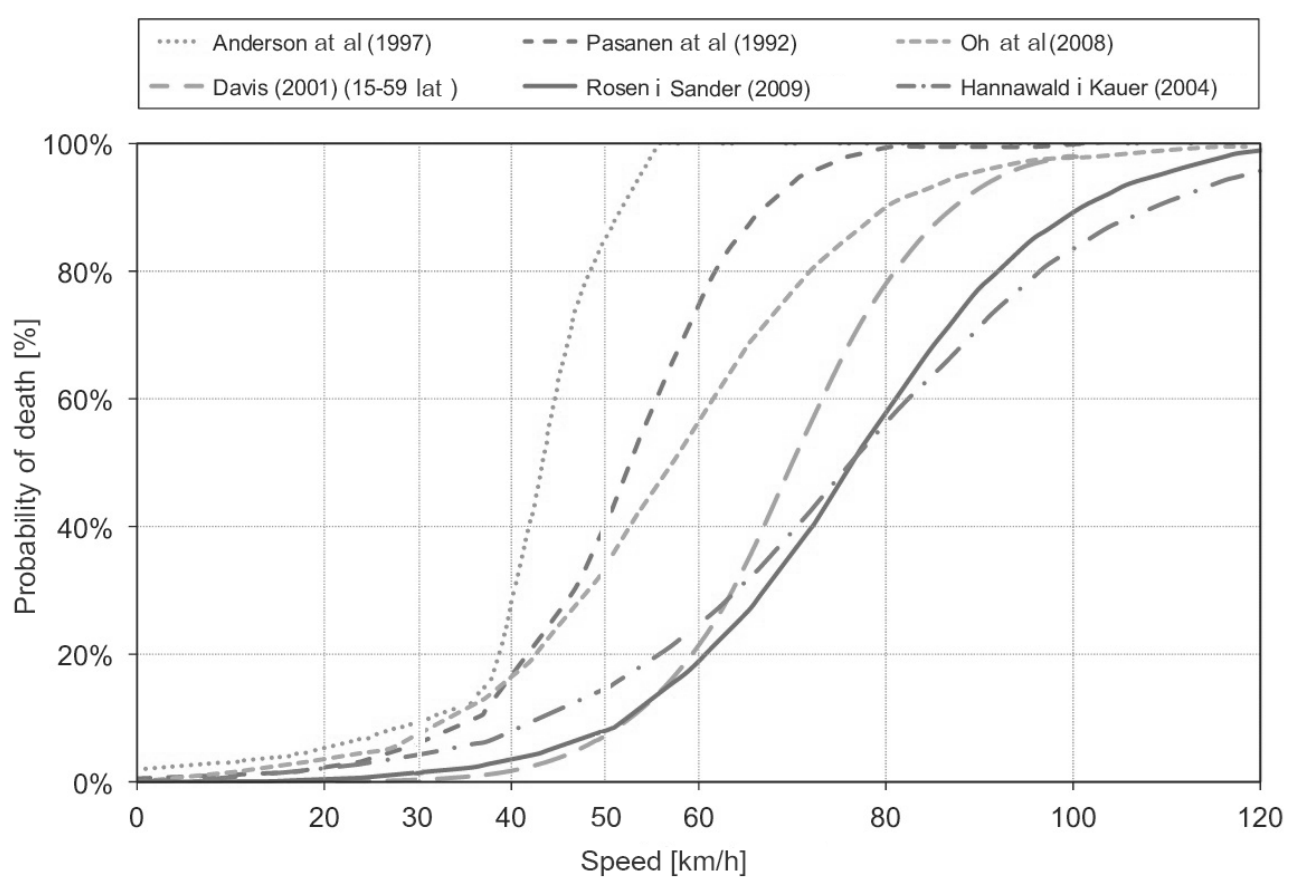

Fig. 3. Probability of pedestrian fatality, based on [7].

The hazards are quite extreme when there are conflicts involving pedestrians and vehicles. This happens when road user interactions are strong and may lead to an accident. If it is to be prevented, one of the road users must take up action to prevent the accident [11]:

- in the case of vehicles: brake, accelerate, change direction;

- in the case of pedestrians: stop, step back, jump to the side, walk faster, start running.

Traffic layout and traffic control around pedestrian crossings are also important [12]. Signalled pedestrian crossings usually allow vehicles to turn in the direction of the arrow on sign, when pedestrians have the green light on. Although they are required to stop before turning right, drivers do not always follow through which puts vulnerable road users at risk. By eliminating the possible driver-pedestrian collision, road safety will improve but the efficiency of the pedestrian crossing or junction is hampered.

Poor road user visibility is key to how a crossing or junction operate. Visibility is reduced as a result of road user behaviour and the dynamics of observer movement. It is important to keep space unobstructed on and around pedestrian crossings [1]. This issue is neglected in Poland, and the only available guidelines can be found in the Road Traffic Law [13] in Article 49.1.2 Vehicles must not stop "on pedestrian crossings, cyclist crossings and not less than 10 $\mathrm{m}$ before the crossing; where double carriageways are concerned, this ban also applies to areas after the crossing".

Key to our operational analyses are behavioural factors both regarding the driver and pedestrian. They comprise a set of mobility reactions which are a human body's response to specific incentives received by the road users through their senses [14]. A change in behaviour may be the result of learning from previously experienced incentives received by sight and hearing. Age and disability are also an important factor. All these features determine the speed of movement, response time, propensity for risky behaviour such as stepping onto the road or driving while the light is red or attempts to cross the street right before a vehicle.

Road elements are also important because they determine the behaviour, traffic parameters and pedestrian and driver responses. The location of the pedestrian crossing is 
equally important. If they are sited close to major traffic generators, it will affect pedestrian and driver volumes, traffic density, time lost and level of service.

There is a multiplicity of factors that determine the operation of pedestrian crossings. They include the weather, environment, lighting and legal regulations. Not all of them can be studied or analysed due to a lack of devices to measure the factors or missing or unreliable data sources. Considering the above, the most relevant factors are identified and divided into three groups:

1. behavioural factors - response time, age, disability;

2. traffic factors - traffic volume, speed of road users, traffic density, acceptable gaps, level of service (LOS), conflict situations;

3. road factors - pedestrian crossing geometry, road and pedestrian facility capacity, visibility of pedestrians and vehicles;

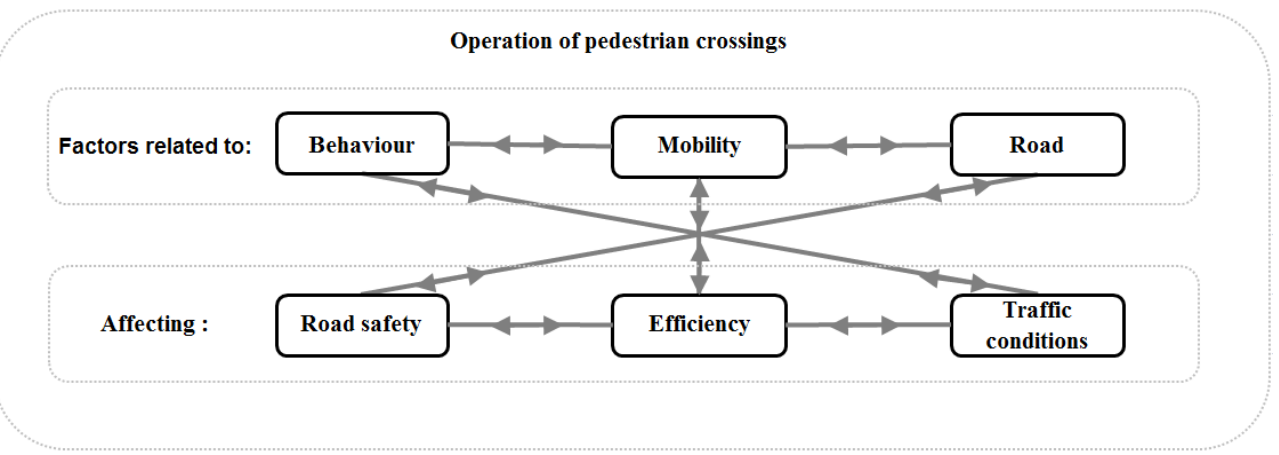

Fig. 4. Factors and features that affect the performance of pedestrian crossings.

\section{Method for studying mean pedestrian walking speed}

One of the parameters within the group of mobility factors is the mean walking speed of pedestrians on crossings. Specific sites were analysed to ensure data reliability. The study included:

- an inventory of pedestrian crossings under analysis to determine the average crossing distance;

- an identification of pedestrian crossing location including the generators of pedestrian traffic;

- video registration of pedestrian behaviour;

- measuring pedestrian volumes.

Four signalled pedestrian crossings were selected, each located on the main streets of Gdynia. Pedestrian behaviour was recorded using the Video Supervision System, part of the TRISTAR Traffic Control System $[15,16]$. It includes wide-angle cameras. The camera was placed at app. $4.5 \mathrm{~m}$ high giving a good view of the entire pedestrian crossing. Video registration was conducted during the afternoon peak $(3.00 \mathrm{pm}$ to $4.00 \mathrm{pm})$ in good weather. After the film material was collected, it was analysed by the observer.

\section{Results}

The video footage was evaluated. It helped to analyse the behaviour of some 870 pedestrians. The following characteristics were recorded: pedestrian volume, age divided into youth and adults (working age) and sex. Table 1 shows the results of walking speed analyses. The highest mean speed was recorded for men $5.2 \mathrm{~km} / \mathrm{h}(1.45 \mathrm{~m} / \mathrm{s})$ and youth $5 \mathrm{~km} / \mathrm{h}(1.40 \mathrm{~m} / \mathrm{s})$ 
and the lowest for older people $3.4 \mathrm{~km} / \mathrm{h}(0.94 \mathrm{~m} / \mathrm{s})$. Mean speed for all groups under analysis was $4.9 \mathrm{~km} / \mathrm{h}(1.36 \mathrm{~m} / \mathrm{s})$. The percentiles $-15 \mathrm{th}, 50$ th and $85 \mathrm{th}$ - were analysed and it was found that $15 \%$ of pedestrians in the analysed population walked at mean speed of up to 4 $\mathrm{km} / \mathrm{h}(1.13 \mathrm{~m} / \mathrm{s}), 50 \%$ of the pedestrians walked at mean speed of up to $4.8 \mathrm{~km} / \mathrm{h}(1.35 \mathrm{~m} / \mathrm{s})$ and $15 \%$ at a speed higher than $5.6 \mathrm{~km} / \mathrm{h}(1.57 \mathrm{~m} / \mathrm{s})$. Figure 5 shows the cumulative distribution of pedestrian speeds on the analysed pedestrian crossings.

Table 1. Mean pedestrian speed.

\begin{tabular}{|c|c|c|c|c|c|c|c|}
\hline \multirow{2}{*}{ Age group } & \multirow{2}{*}{ Sex } & \multirow{2}{*}{ Number } & \multicolumn{2}{|c|}{$\begin{array}{c}\text { Mean pedestrian } \\
\text { speed }\end{array}$} & \multirow{2}{*}{$\begin{array}{c}15^{\text {th }} \\
\text { percentile } \\
{[\mathrm{m} / \mathrm{s}]}\end{array}$} & \multirow{2}{*}{$\begin{array}{c}50^{\text {th }} \\
\text { percentile } \\
{[\mathrm{m} / \mathrm{s}]}\end{array}$} & \multirow{2}{*}{$\begin{array}{c}85^{\text {th }} \\
\text { percentile } \\
{[\mathrm{m} / \mathrm{s}]}\end{array}$} \\
\hline & & & {$[\mathrm{m} / \mathrm{s}]$} & {$[\mathrm{km} / \mathrm{h}]$} & & & \\
\hline \multirow{2}{*}{$\begin{array}{l}\text { Working age } \\
\text { people }\end{array}$} & Women & 412 & 1.34 & 4.83 & 1.14 & 1.34 & 1.55 \\
\hline & Men & 324 & 1.45 & 5.22 & 1.26 & 1.41 & 1.66 \\
\hline Children & N/A & 27 & 1.28 & 4.60 & 1.10 & 1.26 & 1.46 \\
\hline Youth & N/A & 59 & 1.40 & 5.03 & 1.23 & 1.33 & 1.58 \\
\hline Older people & N/A & 45 & 0.94 & 3.40 & 0.79 & 0.97 & 1.14 \\
\hline \multicolumn{2}{|c|}{ TOTAL } & 867 & 1.36 & 4.91 & 1.13 & 1.35 & 1.57 \\
\hline
\end{tabular}

\section{Cumulative distribution of pedestrian speed Signalled junctions ( 867 cases)}

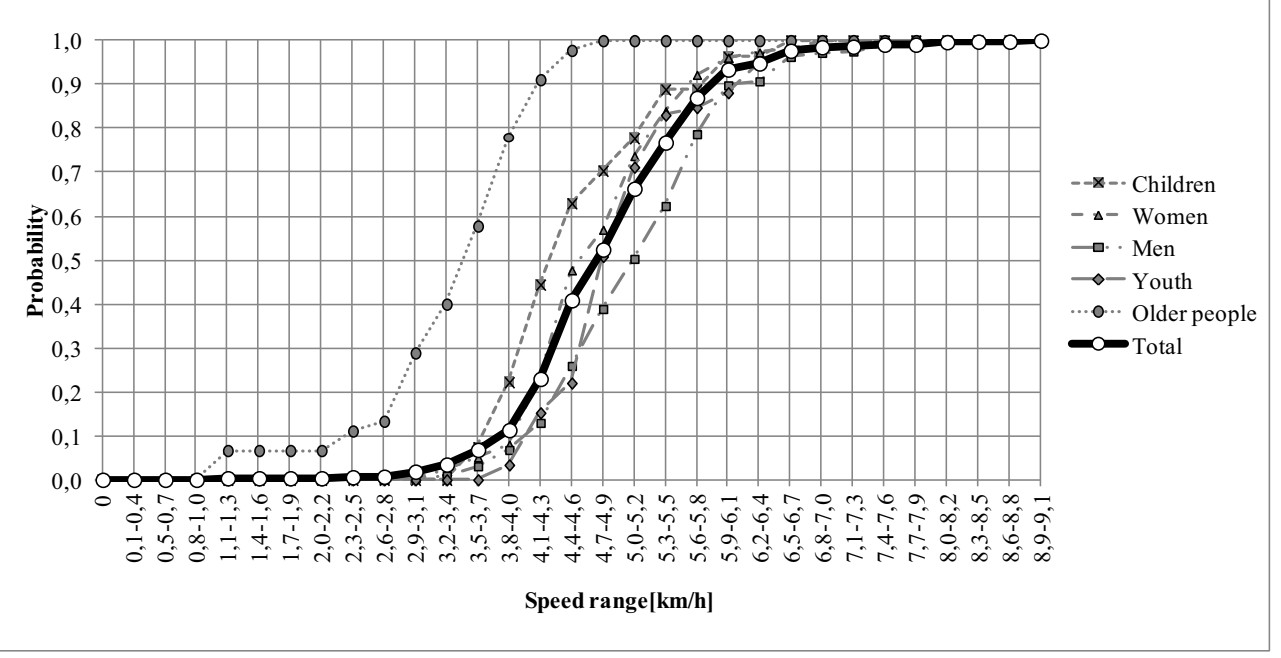

Fig. 4. Cumulative distribution of pedestrian speeds on signalled pedestrian crossings.

\section{Discussion of the results in relation to the literature}

Walking speed is one of the key parameters when designing and optimising the parameters of pedestrian crossing traffic lights. It depends on age, mobility motivation, destination and nature of trip, volume, disability, weather, type of terrain, location and geometry of the 
crossing, traffic layout, traffic control and, in the case of crossings with traffic lights, the part of green time duration which the pedestrian is using to cross the road.

In the 1980s US researchers [17] analysed the speed of pedestrians in free-flow using a sample of 967 pedestrians at a transport terminal in New York City. It was observed that $78 \%$ of the subjects moved at a speed less than $5 \mathrm{~km} / \mathrm{h}(1.4 \mathrm{~m} / \mathrm{sec})$. Mean speed was $4.3 \mathrm{~km} / \mathrm{h}(1.2$ $\mathrm{m} / \mathrm{sec})$, with older men moving at $3.9 \mathrm{~km} / \mathrm{h}(1.1 \mathrm{~m} / \mathrm{sec})$ and representing the $25^{\text {th }}$ percentile of the cumulative distribution function. These results were compared to the study on Gdynia's signalled pedestrian crossings and presented in Fig. 5. As we can see, pedestrians from Gdynia sites moved slightly faster, which in the case of the $50^{\text {th }}$ percentile was app. $0.2 \mathrm{~km} / \mathrm{h}$. The speeds of the pedestrian population studied can be described with normal distribution and standard deviation of 0.89 .

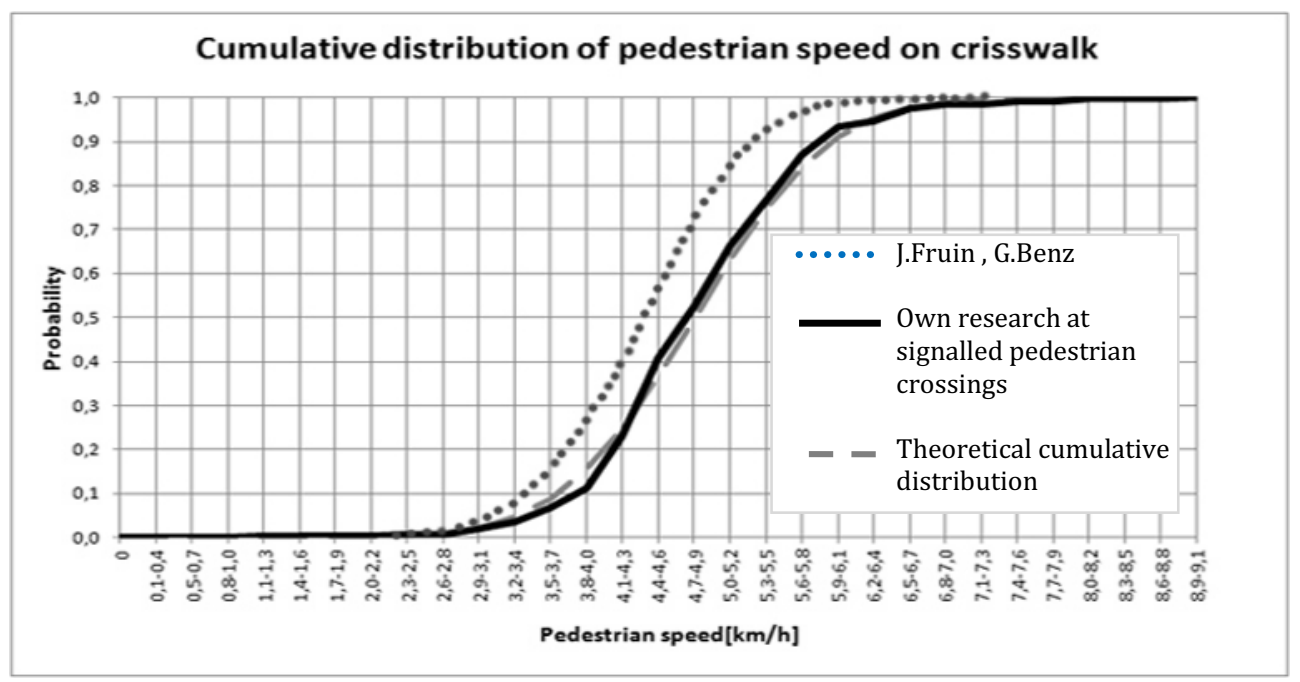

Fig. 5. Comparison of pedestrian speed distribution, based on [15].

\section{Conclusions and recommendations for further research}

More research should be done to include pedestrian crossings with different layouts and control systems. Further work will include the other parameters, for each group of factors that determine the performance of pedestrian crossings. This will later be used to develop mathematical models of pedestrian traffic. There are plans to conduct analyses using the micro-stimulation tool PTV Vissim with Viswalk module and compare the results with site test results. Finally, tools will be developed to help with planning, designing and auditing pedestrian facilities including a method for selecting the technical parameters and evaluating pedestrian crossings.

\section{References}

1. K. Jamroz, S. Gaca, L. Michalski, M. Kieć, M. Budzyński, L. Gumińska, W. Kustra, T. Mackun, I. Oskarbska, J. Rychlewska, A. Ryś, J. Wachnicka, J. Wierzbicka, Protection of Pedestrians. Guidelines for pedestrian traffic organizers (in Polish) (National Road Safety Council, Gdansk, Warsaw, Cracow, 2014)

2. Regulation of the Minister of Transport and Maritime Economy of 2 March 1999 on technical conditions for public roads and their location, OJ 1999 No. 43 Pos. 430 (Poland, 1999) 
3. P.Olszewski, I.Buttler, W.Czajkowski, P.Dąbkowski, C.Kraśkiewicz, P.Szagała, A.Zielińska, Pedestrian safety assessment with video analysis, Transp. Res. Procedia. 14 pp. 2044-2053 (2016)

4. http://stats.oecd.org/\#, (2016)

5. http://www.its.waw.pl/cms/domena_its/Piesi,0,3254,1.html, (2016)

6. E. Rosen, U. Sander, Pedestrian Fatality Risk as a Function of Car Impact Speed, Accid. Anal. Prev. 41 pp. 536-542 (2009)

7. J. Hu, K.D. Klinich, Toward designing pedestrian-friendly vehicles. Report no. Umtri2012-19 (The University of Michigan, Transportation Research Institute, Michigan, 2012)

8. L. Hannawald, F. Kauer, ACEA Ehwal Effectiveness Study (Technische Universitat Dresden, 2004)

9. E. Roséna, H. Stigsonb, U. Sandera, Literature review of pedestrian fatality risk as a function of car impact speed (Sweden, 2011)

10. G. Davis, Relating severity of pedestrian injury to impact speed in vehicle-pedestrian crashes - Simple threshold model, TRB J. Transp. Res. Board. pp. 108-113 (2001)

11. R. Krystek, K. Jamroz, L. Michalski, R. Marszałek, Technika konfliktów ruchowych, (1991)

12. J. Oskarbski, L. Gumińska, M. Miszewski, I. Oskarbska, Analysis of signalized intersections in the context of pedestrian traffic, Transp. Res. Procedia. 14 pp. 21382147 (2016)

13. Act of 20 June 1997 - Road Traffic Act, OJ 1997 No. 98 Pos. 602 (Poland, 1997)

14. W.J. Broadus, Behavior, An Introduction to Comparative Psychology (Henry Holt and Company, New York, 1914)

15. J. Oskarbski., K. Jamroz, Reliability and safety as an objective of intelligent transport systems in urban areas, J. KONBiN. 2(34) pp. 59-70 (2015). doi:10.1515/jok-20150024

16. J. Oskarbski, Perspectives of Telematics Implementation in Tri-City Transport Systems Management and Planning, Commun. Comput. Inf. Sci. 239 pp. 233-240 (2011)

17. C.V.Z. Brian, L. Bowman, J.J. Fruin, Planning Design and Maintenance of Pedestrian Facilities (Federal Highway Administration, 1989) 